\title{
LEADER OF THE PACK
}

Saudi Arabia leads the way in scientific research in the Arab world, but its position at the top of the pile is reliant on relatively few institutions. By Richard Hodson, infographic by Mohamed Ashour. Data analysis by Aaron Ballagh and Alexander Scherrmann.

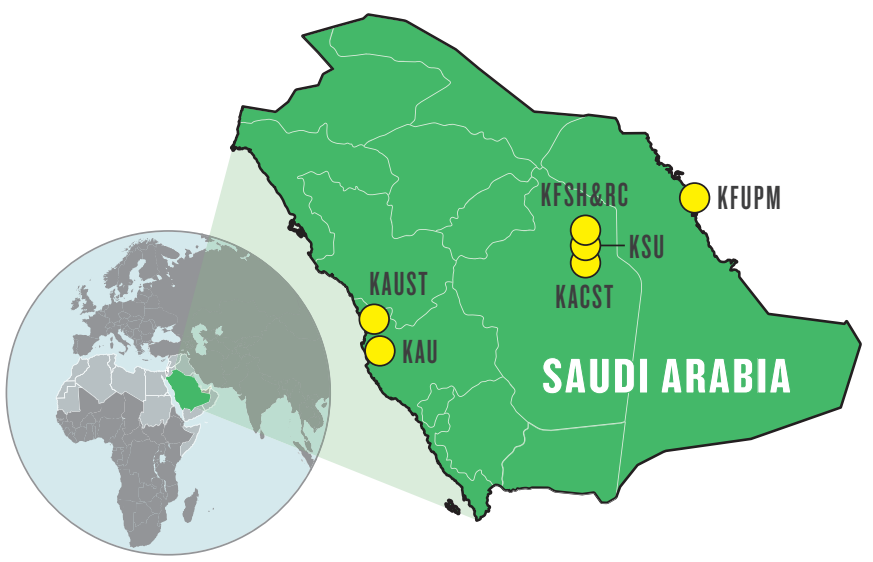

\section{ARABIAN POWERHOUSE}

Saudi Arabia is ranked just outside the top 30 nations for high-quality research, 19 places higher than its closest competitor in the Arab world, the United Arab Emirates (a). It maintained its lead over its Arab neighbours in 2016, though Qatar jumped 9 places up the global rankings last year, making it the fastest climber at the top of Arabian research. Despite these gains on the global leaderboard, however, the gulf between Saudi Arabia and its Arab neighbours in terms of the country's contribution to high-quality research remains extremely large (b).

Saudi Arabia

a)

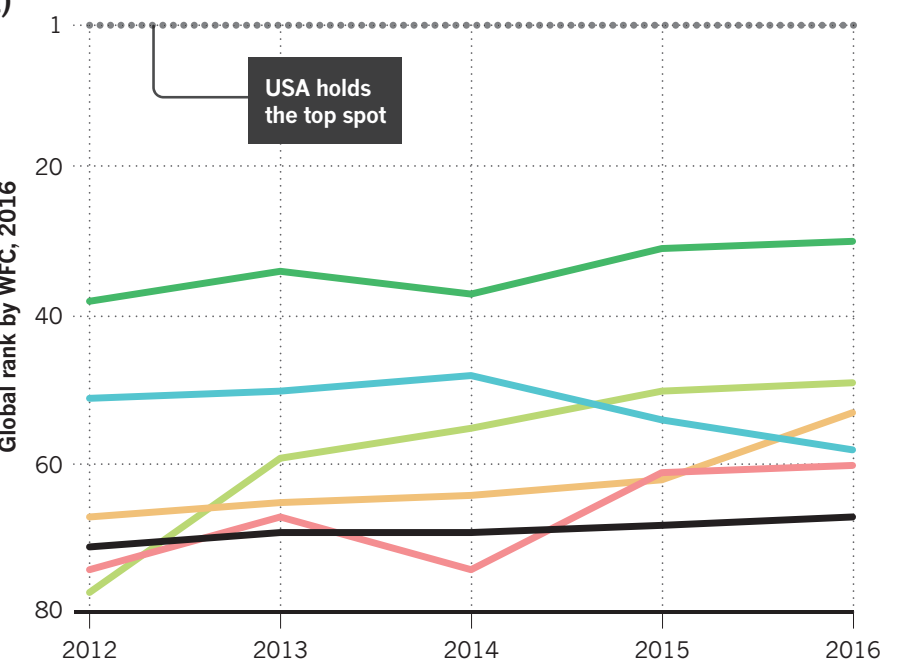

Egypt

Morocco

Lebanon

b)

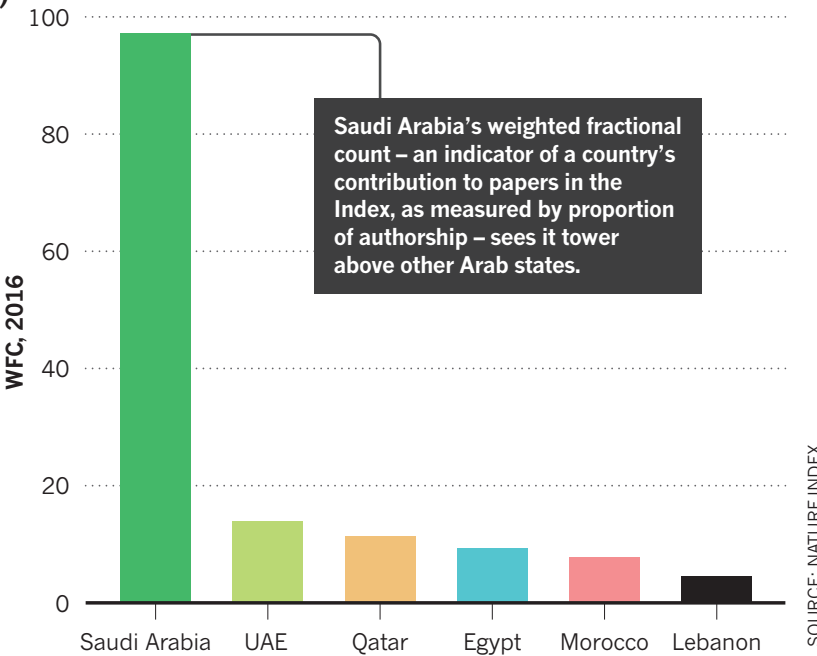

\section{SUBJECT STRENGTH}

Chemistry is Saudi Arabia's forte, and the main driver of its rise up the Nature Index rankings since 2012. But the physical sciences, a distant second for the past two years, narrowed to gap in 2016. Despite AC remaining relatively unchanged, WFC increased in 2016 . This shows that Saudi Arabian authors made a greater contribution to the physical science papers they published than in 2015. A similar change was also seen in chemistry and the life sciences last year.

CHEMISTRY

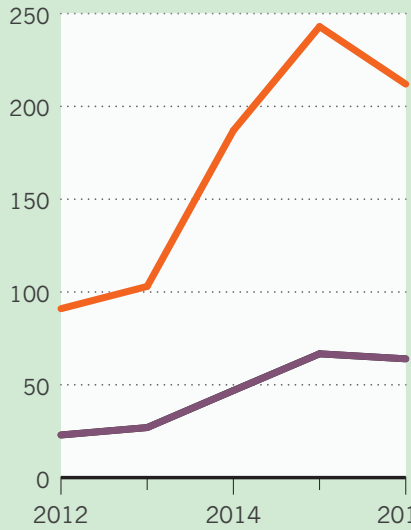

PHYSICAL SCIENCES

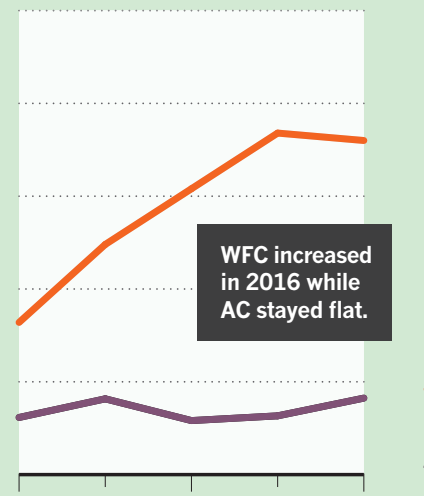

LIFE SCIENCES

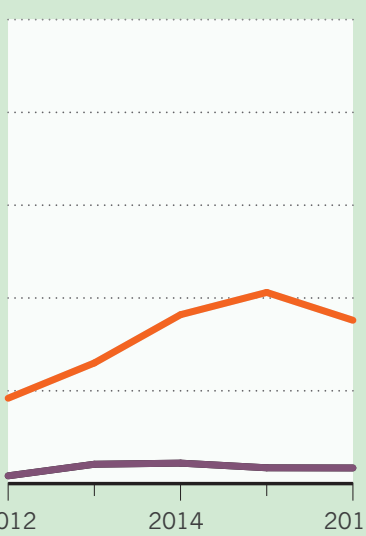

EARTH AND ENVIRONMENTAL SCIENCES

- Article count (AC)

- Weighted fractional count (WFC)

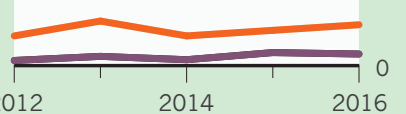




\section{RESEARCH SPENDING}

Saudi Arabia ranks 44th in the world for gross domestic expenditure on R\&D (GERD) as a percentage of gross domestic product (GDP),

based on the latest available data (2013). The United Arab Emirates invests a similar proportion of its GDP in research.

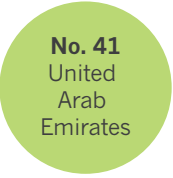

$0.87 \%$

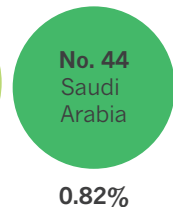

GERD (\% of GDP)

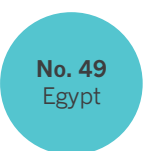

$0.72 \%$

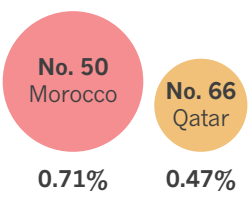

$0.71 \% \quad 0.47 \%$

\section{IN THE MONEY}

A sharp increase in R\&D funding in Saudi Arabia in 2010 was matched by an upswing in the quantity of Saudi research. The level of funding is, however, well below the OECD average of $2.4 \%$.
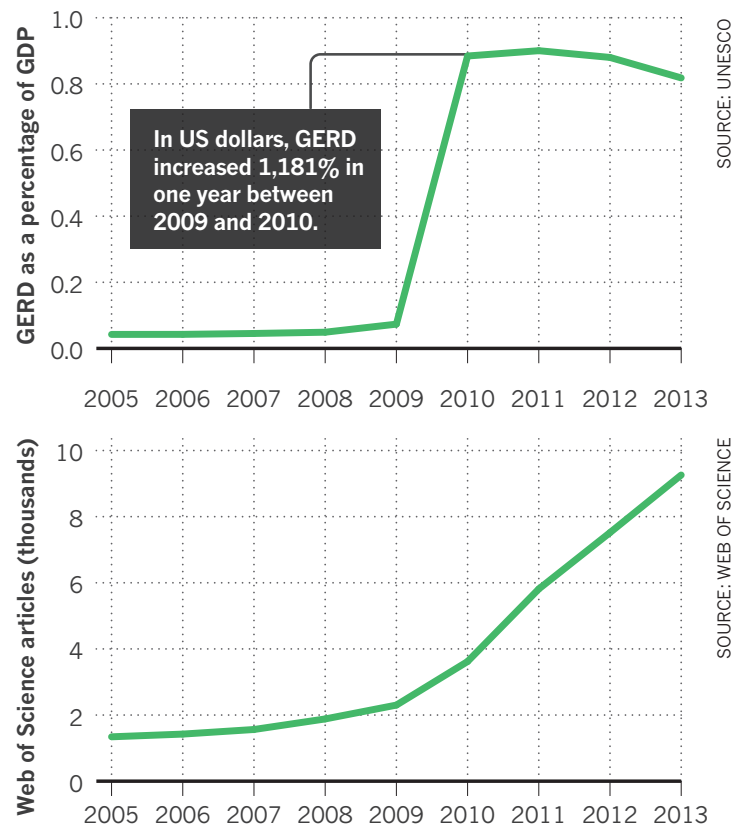

\section{INVESTMENT AREAS}

The natural sciences attract the most funding in Saudi Arabia, and make up the bulk of research publications. The quantity of research produced in engineering and in the health sciences is closer than spending on the two fields might suggest.

Natural Engineering Medical and Agricultural Social sciences and technology health sciences sciences sciences

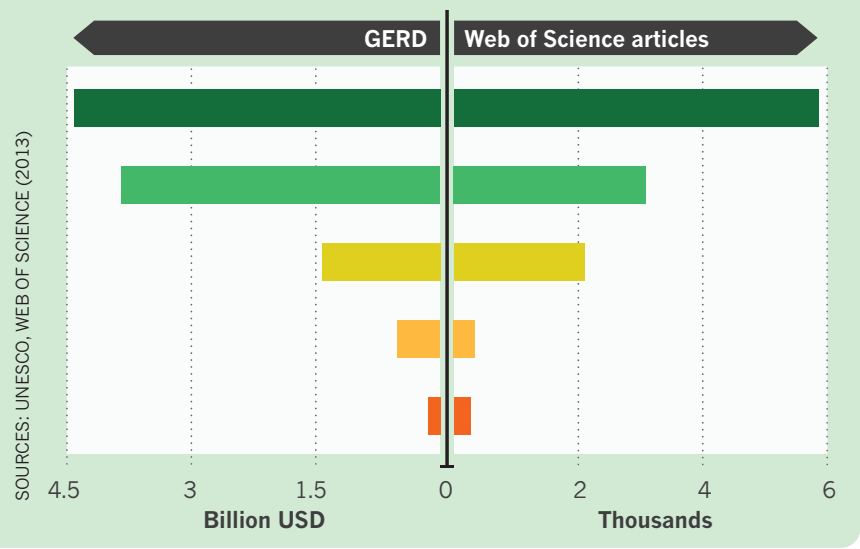

\section{WHO'S DRIVING SAUDI RESEARCH?}

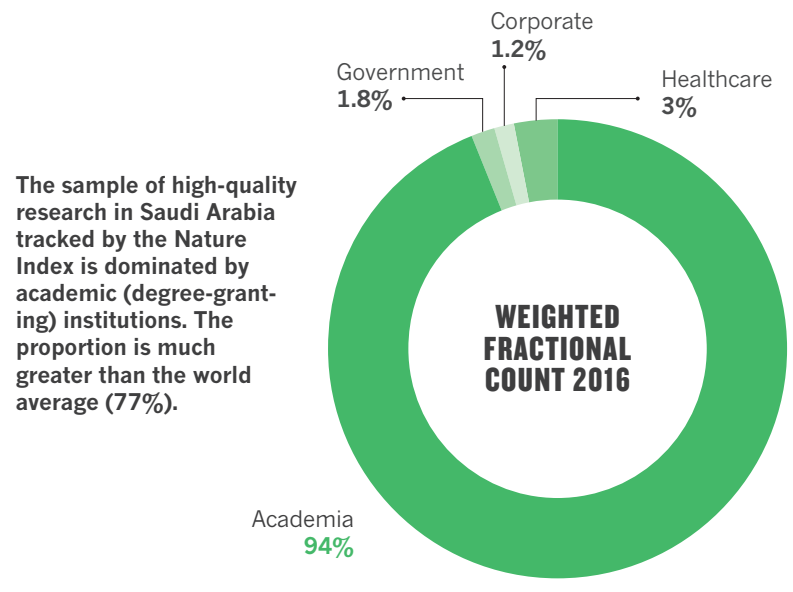

\section{THE BIG SIX}

Just six institutions account for $95 \%$ of Saudi Arabian research, according to WFC (2016).

\section{KAU $11.2 \%$}

Others $5.2 \%$ KACST $1.5 \%$. KFUPM $1.8 \%$
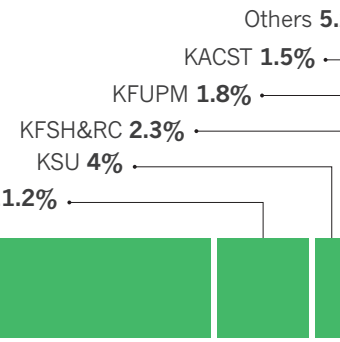

There's more to research excellence than just quantity of papers. Larger institutions naturally produce more papers than smaller ones. Adjusting for the size advantage (based on an institution's total output of natural science articles in the Web of Science), government body KACST has the highest number of high-quality articles in Index-tracked journals. However, by WFC - which takes into account an institution's contribution to multi-authored papers - KAUST is the clear leader.

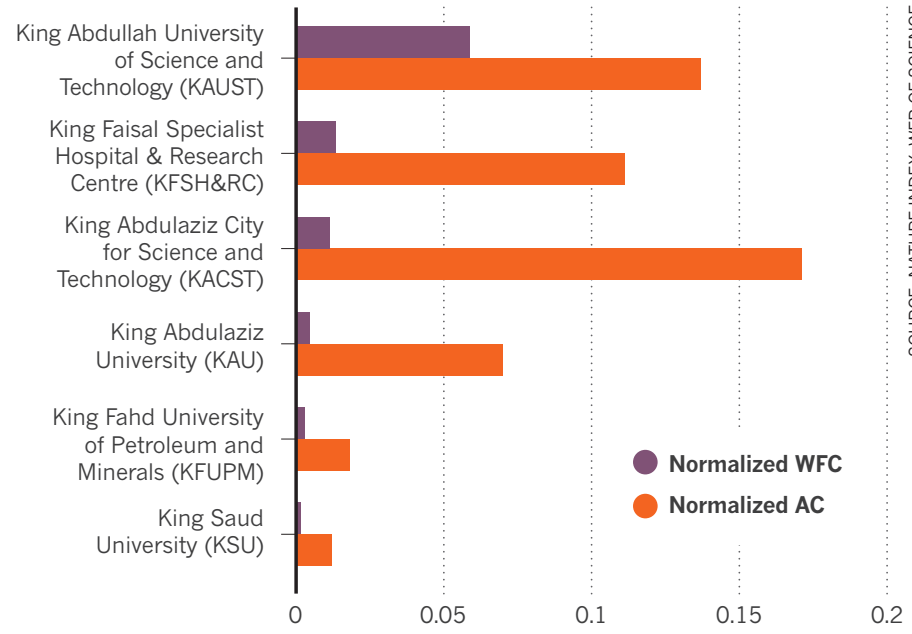

WFC and AC, adjusted for institution size (2016)

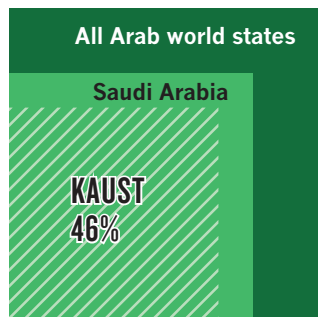

In 2016, KAUST was the principal source of high-quality research by WFC not just in Saudi Arabia, but the entire Arab world. Its researchers account for nearly half the region's WFC. 